\title{
Death and life: Muricid snails consume the vermetid gastropod, Dendropoma maximum, and use empty shells for reproduction
}
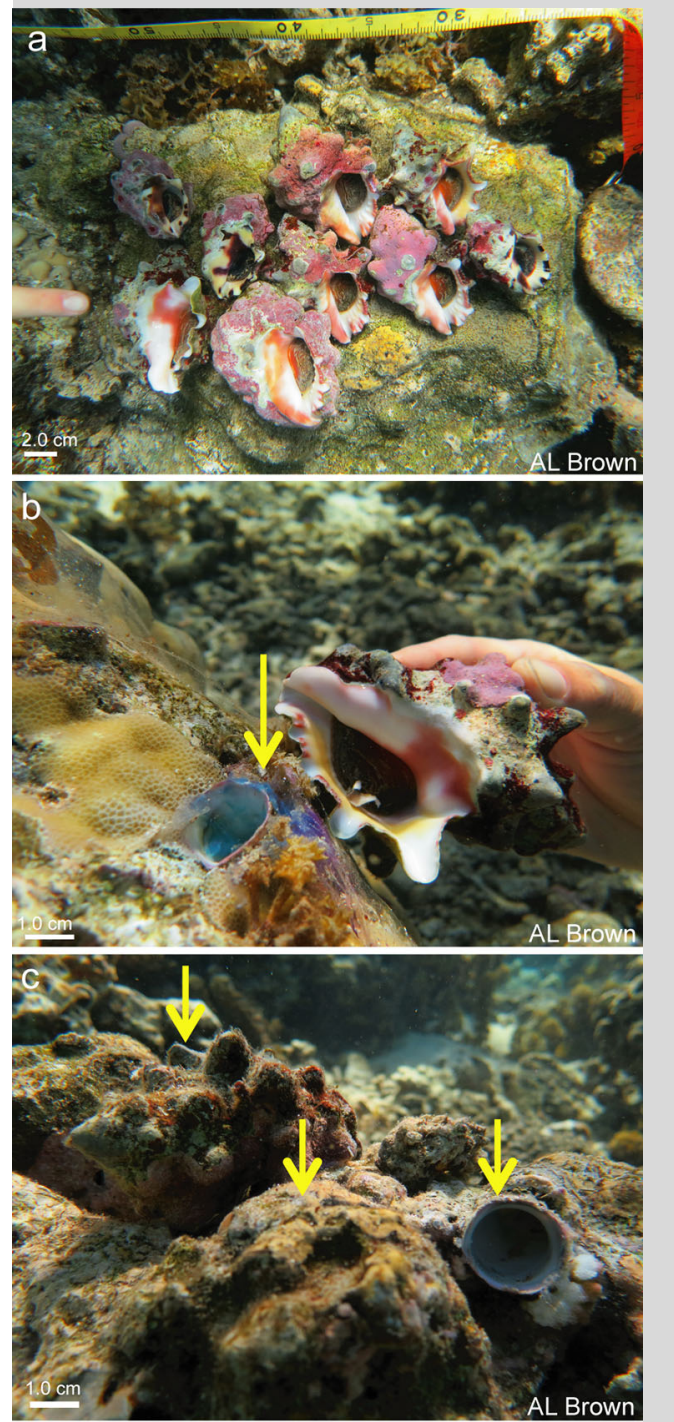

d
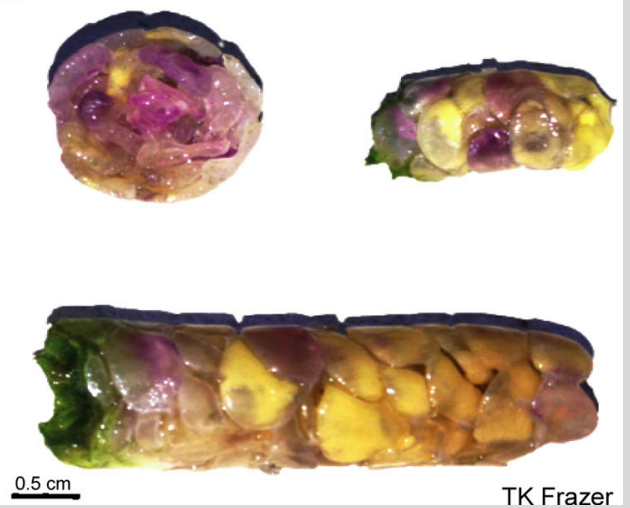

Dendropoma maximum, a large sessile vermetid gastropod, is abundant on shallow coral reefs and can reduce the growth and survival of corals (Shima et al. 2010). Despite high densities and detrimental effects, little is known about vermetid ecology, particularly their interactions with predators. In the austral winter, we observed two species of muricid gastropods, Mancinella armigera (Link, 1807) and Menathais tuberosa (Röding, 1798; Fig. 1a) feeding on the vermetid gastropod, D. maximum, in the shallow lagoon of Moorea, French Polynesia (17.28 $\left.525-645^{\prime} \mathrm{S}, 149.47^{\circ} 335-535^{\prime} \mathrm{W}\right)$. Until now, vermetid predation had not been documented in French Polynesia, although $M$. amigera had been reported to consume vermetids in other areas of the South Pacific (Taylor 1976). On five occasions, we observed M. armigera with its proboscis inserted into a shell of $D$. maximum. When the muricid was removed, a blue substance was observed in the empty vermetid shell tube (Fig. 1b), along with the operculum of the $D$. maximum. In addition to these field observations, we placed live vermetids and muricids in lab aquaria together and observed an additional five predation events. In the field, we found a greater number of $D$. maximum recently killed (Fig. 1c) within $1 \mathrm{~m}$ of a $M$. amigera than in nearby (within $3 \mathrm{~m}$ ) control plots lacking $M$. amigera $\left(t_{4}=-3.06\right.$, $p=0.02,4 \pm 2.3$; vs. $0.2 \pm 0.4$, mean $\pm 95 \%$ confidence interval, $n=5$ ), suggesting that the predator may represent a significant source of mortality for vermetids.

During our surveys, we also discovered egg masses from muricids deposited into vermetid shells (Fig. 1d). In one instance, we observed recently deposited egg cases when removing a $M$. armigera from atop a $D$. maximum. In all other instances, the egg cases were found near pairs of $M$. armigera, suggesting that those snails deposited the eggs. The use of shells of recently killed vermetids for reproduction has not been reported previously. This interaction represents a novel use of a prey resource, in which the consumption of a prey also facilitates the predator's reproduction by creating a new microhabitat for eggs.

Acknowledgments We thank G. Paulay for helpful discussion, the Richard B. Gump Field Station for facilitating our work, and the National Science Foundation for funding (OCE-1130359).

\section{References}

Shima J, Osenberg C, Stier A (2010) The vermetid gastropod Dendropoma maximum reduces coral growth and survival. Biol Lett 6:815

Taylor JD (1976) Habitats, abundancez and diets of muricacean gastropods at Aldabra Atoll. Zool J Linn Soc 59:155-193

A. L. Brown $(\bowtie) \cdot$ J. Zill · C. W. Osenberg

Department of Biology, University of Florida, Gainesville, FL 32611, USA

e-mail: anyabrown@ufl.edu

T. K. Frazer

School of Natural Resources and Environment, University of Florida, Gainesville, FL 32611, USA

Fig. 1 a Mancinella armigera (rosy aperture) and Menathais tuberosa (black stripes on aperture) collected within $3 \mathrm{~m}$ of recently consumed vermetids. The $M$. armigera in the lower left of the group (see finger) was found feeding on a vermetid and is also shown in $\mathbf{b}$ M. armigera with a vermetid shell. The arrow points to the blue material that emerged when the predatory snail was removed from the vermetid. $\mathbf{c}$ Two muricids (left-most arrows) near a recently killed vermetid (right arrow). $\mathbf{d}$ Top and two side views of two out of the four egg masses found inside a vermetid shell that was near two live $M$. armigera

Received: 22 November 2013/Accepted: 4 March 2014/Published online: 25 March 2014

Coral Reefs (2014) 33:497

(C) Springer-Verlag Berlin Heidelberg 2014
DOI 10.1007/s00338-014-1141-6 